\title{
Serviço Social na política de saúde no enfrentamento da pandemia da covid-19
}

\section{Social Work in health policy facing the covid-19's pandemic}

\author{
Raquel Cavalcante Soares ${ }^{a}$ \\ (D) https://orcid.org/0000-0002-1276-5540 \\ Maria Valéria Costa Correia \\ (D) https://orcid.org/0000-0002-0372-7251 \\ Viviane Medeiros dos Santos ${ }^{b}$ \\ (D) https://orcid.org/0000-0003-0274-8066
}

\begin{abstract}
Resumo: $O$ presente artigo objetiva discutir as principais tendências do trabalho profissional de assistentes sociais na política de saúde no enfrentamento da pandemia da covid-19. Para isso, fazemos uma breve discussão dos principais elementos da política de saúde no governo Bolsonaro e, posteriormente, analisamos as inflexões para o Serviço Social na dimensão do trabalho e no lugar da profissão, suas demandas, estratégias e contribuições na linha de frente à pandemia.
\end{abstract}

Palavras-chave: Covid-19. Política de saúde. Serviço Social.

\begin{abstract}
This article aims to discuss the main trends in the professional work of social workers in health policy facing the covid-19 pandemic, the challenges and demands on Social Work. For this, we briefly discuss the main elements of health policy in the Bolsonaro Government and, later, we analyze the inflections for Social Work in the dimension of work and in the place of the profession, its demands, strategies and contributions in the front line to the pandemic.
\end{abstract}

Keywords: Covid-19. Health policy. Social Work. 


\section{Introdução}

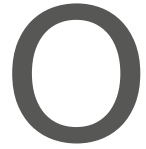

governo federal, no contexto da maior crise sanitária de dimensão planetária, tem minimizado a pandemia da covid-19, em função do seu projeto de extrema direita que coloca o lucro acima da vida, banalizando as mortes. A política genocida que foi adotada pelo governo, seu caráter negacionista, ultraliberal e protofascista, ${ }^{2}$ não considera as evidências científicas, oculta dados, naturaliza as mortes e provoca a flexibilização das medidas recomendadas pela ciência e pela Organização Mundial da Saúde (OMS) em nome do mercado.

Diante dessa complexidade, o Serviço Social tem sido convocado para atuar, junto com os(as) demais trabalhadores(as) da saúde, na linha de frente no enfrentamento da covid-19. Em meio a condições de trabalho precárias e, muitas vezes, como trabalhador(a) precarizado(a), com vínculos temporários, assistentes sociais em todo o país tiveram que lidar, inclusive, com demandas não condizentes com suas atribuições profissionais. Todavia, contraditoriamente, exercitaram sua relativa autonomia profissional com capacidade propositiva, a partir dos fundamentos do projeto ético-político profissional, na resistência em defesa da vida e dos direitos de todos(as).

\section{A política de desarticulação do enfrentamento da covid-19 no governo Bolsonaro}

A pandemia da covid-19 vem causando consequências econômicas, políticas e sociais, configurando-se como a maior crise sanitária

1 Doença causada pelo coronavírus SARS-CoV-2, considerada uma pandemia pela Organização Mundial da Saúde, em 11 de março de 2020 (Opas Brasil, 2020).

2 Nos termos de Virgínia Fontes (2019), o governo Bolsonaro "tem viés nitidamente protofascista, lastreado centralmente em um anticomunismo primário, que considera todas as demais forças sociais diferentes de si mesmo como alvos de sua 'caça às bruxas'. O lema 'Deus, pátria e família', verbalizado por expoentes do novo governo, faz lembrar tanto o velho integralismo 
da humanidade. O mundo já contabiliza, segundo dados da OMS de 11/10/2020, um total de 1.056.186 mortes. No Brasil, segundo o Ministério da Saúde, até a mesma data, já eram 150.488 mil mortes causadas pela covid-19 (Brasil, 2020a). É necessário ressaltar o caráter histórico e a determinação social da pandemia, tendo em vista a racionalidade e o caráter destrutivo da sociabilidade capitalista contemporânea, inclusive na sua mediação com o meio ambiente, e na configuração como a covid-19 se espraiou mundialmente, agudizando as desigualdades sociais existentes.

Apesar do consenso entre os especialistas, o presidente Bolsonaro colocou em dúvida tanto a gravidade quanto o alto número de casos e óbitos computados. ${ }^{3}$ Além disso, uma característica importante do seu governo tem sido a inexistência de uma intervenção nacional consolidada, com orientações para estados e municípios, promovendo, intencionalmente, uma fragmentação de decisões por parte dos governos estaduais e municipais.

Antes da chegada do vírus no Brasil, o contexto no país já era assolador para a maioria da população brasileira, com o aprofundamento e a aceleração da contrarreforma do Estado e suas particularidades na política de saúde nos governos Michel Temer e Jair Bolsonaro. Segundo Bravo, Pelaez e Menezes (2020), há nesses governos uma atualização do projeto privatista da saúde na configuração de um projeto que defende um Sistema Único de Saúde (SUS) completamente submetido aos interesses do mercado privado. Em meio às diversas ações de desmonte da seguridade social, a de maior magnitude em termos de devastação do

(fascismo à brasileira, fundado em 1932 e que desaparece na década de 1970, com seus militantes absorvidos por outros partidos) quanto a divisa da hiper-reacionária Tradição, Família e Propriedade (católica), que renasce das cinzas após essas eleições, tendo um grupo paramilitar realizado rituais de destruição de bandeiras antifascistas em universidades públicas.

3 Conforme as frases proferidas em 15 de março de 2020: “Não podemos entrar em uma neurose como se fosse o fim do mundo [...]. Com toda certeza há um interesse econômico nisso tudo para que se chegue a essa histeria”, e em 27 de março de 2020: “'Não estou acreditando nesses números' -3.417 casos e 92 mortes" (Tajra, 2020). 
sistema de proteção social brasileiro foi a aprovação da Emenda Constitucional no 95, que instituiu um novo regime fiscal que congelou os gastos primários por vinte anos, entre eles os investimentos em políticas sociais. Esse dispositivo constitucional subtraiu do SUS, nos anos de 2018 a 2020, cerca de 22,5 bilhões de reais, configurando-se, desde então, um processo de desfinanciamento da política de saúde e, consequentemente, engendrando um aprofundamento de sua precarização (CNS, 2020b).

Por outro lado, em 23 de abril, o governo Bolsonaro liberou $\mathrm{R} \$ 1,216$ trilhão para o sistema financeiro, sob o argumento de combater os impactos negativos da pandemia, visando manter a continuidade das suas operações. Tal cifra representa $16,7 \%$ do Produto Interno Bruto (PIB) (Agência Estado, 2020). Enquanto isso, dos recursos destinados ao Ministério da Saúde para o enfrentamento da covid-19, apenas 30\% haviam sido efetivamente gastos até o final de julho de 2020.

Todavia, o governo federal tem sido eficiente para garantir o fortalecimento e a estabilidade do setor privado da saúde, inclusive durante a pandemia: não houve gestão no sentido de instituir fila única (sistema público e privado) de assistência à saúde de usuários(as) com covid-19. A Agência Nacional de Saúde Suplementar (ANS) muitas vezes, por ausência e indefinição, beneficiou os planos privados de saúde, ${ }^{4}$ outras vezes instituiu medidas para flexibilização das normas que regulamentam os planos e seguros privados de assistência à saúde, assim como a liberação de recursos, os quais poderiam estar sendo investidos no SUS ${ }^{5}$ (Correia e Alves, 2020).

De fato, o processo de privatização do SUS continuou sendo ampliado durante a pandemia com o repasse da gestão de muitos hospitais de campanha para os modelos privatizantes por meio da contratualização

4 Como foi o caso da aprovação da inserção de testes sorológicos para detecção da covid-19 que só foi feita em 29/6/2020, em decorrência de uma ação civil pública.

5 De acordo com Correia e Alves (2020), a ANS realizou algumas concessões que, somadas a outras medidas, preveem a liberação do total de cerca de $\mathrm{R} \$ 15$ bilhões para as operadoras de saúde no enfrentamento da covid-19. 
de Organizações Sociais (OS), especialmente. Entretanto, os escândalos envolvendo o desvio de recursos públicos ${ }^{6}$ da saúde por meio das OS têm sido evidenciados também nesse período.

No contexto de desmonte das políticas sociais e agravamento das desigualdades sociais, a determinação social do processo saúde e doença influencia tanto as condições de enfrentamento quanto os óbitos relacionados à covid-19.

A primeira recomendação para prevenir o contágio pelo coronavírus foi lavar as mãos. Mas como higienizar as mãos se, de acordo com o Sistema Nacional de Informações sobre Saneamento (SNIS, 2018), 33.129.083 milhões de brasileiras/os não têm acesso a água encanada e 1.717 .980 milhões de habitações sequer têm banheiro dentro de casa? [...] 0 país tem 12,8 milhões de desempregados e 30,8 milhões de trabalhadores informais. (Correia e Alves, 2020, p. 11)

Por fim, no tocante à gestão do Ministério da Saúde, durante a pandemia, o governo Bolsonaro nomeou três ministros diferentes ${ }^{7}$ para o cargo, sendo o último deles, Eduardo Pazuello, um militar que vem implementando um processo de militarização do ministério e de desestruturação da sua base técnica. Todo o seu primeiro escalão é integrado por militares sem experiência ou formação na área de saúde. Ademais, têm sido realizados movimentos no sentido de restringir o acesso à informação e a dados sobre a pandemia e a gestão da política.

6 Durante esse período a Polícia Federal, em conjunto com a Controladoria-Geral da União, realizou a operação S.O.S, que constatou só no governo do estado do Pará a celebração de contratos com OS envolvendo a cifra de R\$1,2 bilhão (Polícia Federal, 2020). No estado do Rio de Janeiro, o desvio de recursos públicos da saúde envolvendo as Organizações Sociais, segundo investigações, chegou a cerca de $\mathrm{R} \$ 1,8$ bilhão, entre 2007 e 2020 (Coelho e Brito, 2020).

7 O primeiro ministro, Luís Henrique Mandetta, apesar de representar os interesses privatistas, tentou conferir um mínimo de racionalidade científica ao enfrentamento da pandemia, a despeito de não questionar o parco aporte de recursos e outras medidas mais ampliadas de enfrentamento. $\mathrm{O}$ segundo ministro, Nelson Teich, não tinha nenhuma experiência de gestão no SUS e também representava interesses do mercado privado, tendo construído sua carreira nesse setor. Ambos deixaram o ministério (ou foram demitidos) pela falta de alinhamento científico com as posições negacionistas do presidente Jair Bolsonaro. 
Diante do exposto, pode-se afirmar que a pandemia da covid-19 no Brasil desvelou ainda mais o projeto protofascista do governo Bolsonaro, que contribuiu de forma decisiva para a morte de milhares de brasileiros, sobretudo pretos e pobres. Ao não investir recursos suficientes e de forma racional, ao não articular a política em nível federal, ao apresentar um discurso negacionista e não alinhado com as recomendações da OMS e ao desestruturar tecnicamente o órgão gestor máximo da política de saúde. Enfim, ao contrário de articular e organizar o enfrentamento, a política de saúde do governo federal desarticulou e desorganizou as respostas necessárias e urgentes requeridas.

No entanto, essas medidas têm enfrentado resistência de vários setores da sociedade, pesquisadores e movimentos sociais que resgatam os princípios da Reforma Sanitária. Dentre esses movimentos, destacam-se os fóruns e frentes, como a Frente pela Vida e a Frente Nacional Contra a Privatização da Saúde (FNCPS). Além disso, no âmbito do controle social institucionalizado, o Conselho Nacional de Saúde (CNS) vem se constituindo um importante espaço de resistência e de aglutinação do movimento sanitário na defesa do SUS e da população brasileira. ${ }^{8}$ Sem dúvida, a maior de todas as resistências tem sido a dos(as) trabalhadores(as) da saúde, que diuturnamente atuam na defesa da vida e da assistência à saúde da população, entre esses, os(as) assistentes sociais.

\section{O trabalho profissional na linha de frente da pandemia: o Serviço Social não fugiu à luta}

É nesse cenário de grande complexidade que o Serviço Social é convocado ${ }^{9}$ a atuar no enfrentamento da covid-19 na política de saúde.

8 Entre as ações realizadas, como reuniões públicas, audiências, divulgação de notas e recomendações, a exemplo da Recomendação no 22, de 9 de abril de 2020, que indica "medidas com vistas a garantir as condições sanitárias e de proteção social para fazer frente às necessidades emergenciais da população diante da pandemia da covid-19" (CNS, 2020).

9 Uma das expressões dessa convocação foi a publicação da Portaria no 639 pelo Ministério da Saúde, que instituiu a "ação estratégica O Brasil Conta Comigo - Profissionais da Saúde, 
A princípio, podem ser elencadas duas grandes ordens de inflexão no trabalho de assistentes sociais na política de saúde nesse contexto: a primeira delas está relacionada diretamente à sua condição de trabalhador; a segunda diz respeito ao seu lugar na política de saúde e às demandas e atribuições requisitadas aos profissionais.

No tocante à condição de trabalhador da saúde, as contratações de assistentes sociais expressam cada vez mais a precarização e a profunda privatização da política de saúde. No bojo das estratégias de enfrentamento da covid-19, a maior parte da expansão dos serviços de saúde se deu via terceirização da gestão em saúde, conforme já discutimos, e, portanto, com contratos precários, inseguros e temporários de trabalho, além da histórica tendência de baixas remunerações. Ademais, no momento da pandemia houve um aprofundamento da plantonização da organização do trabalho profissional - inclusive utilizada como estratégia de menor exposição e risco do(a) trabalhador(a). Contudo, contraditoriamente, em muitos serviços tal estratégia intensificou a precarização das condições de trabalho e de riscos e agravos à saúde. Isto porque tem sido relativamente frequente a realização de plantões com duração de 24 horas de trabalho, caracterizando-se como extenuantes e que põem em risco tanto a saúde de profissionais quanto a qualidade dos serviços prestados.

Importa ressaltar que houve uma pequena expansão de vínculos profissionais de assistentes sociais em serviços de saúde nesse período. De fato, dados do Cadastro Nacional de Estabelecimentos de Saúde (CNES) expressam um aumento no ritmo de contratação de assistentes sociais entre dezembro de 2019 (39.441 vínculos) e junho de 2020 (40.911 vínculos), possivelmente relacionado à expansão dos serviços de emergência, internamento e Unidades de Terapia Intensiva (UTI), em decorrência da pandemia. ${ }^{10} \mathrm{O}$ aumento foi de $3,72 \%$ em seis meses, enquanto em todo o

voltada à capacitação e ao cadastramento de profissionais da área de saúde, para o enfrentamento à pandemia". Entre os profissionais convocados figuram no primeiro lugar da lista os(as) assistentes sociais (Brasil, 2020d,).

10 Segundo levantamento realizado pela CNN Brasil, até maio de 2020 foram criados 94 hospitais de campanha no Brasil, que perfaziam um total de 9.914 leitos. Observa-se, no entanto, que 
ano anterior havia sido de 3,4\% (Brasil, 2020b). Todavia, ainda abaixo do ritmo de contratação que Soares (2020) denominou de ampliação restrita, nos governos do Partido dos Trabalhadores.

No primeiro momento, grande parte de assistentes sociais teve que lidar com dois importantes tensionamentos: as dificuldades de acesso a equipamentos de proteção individual (EPI) e a demarcação de suas atribuições e competências profissionais. Principalmente na fase inicial de enfrentamento da pandemia, houve escassez na disponibilidade de EPI em diversos serviços, e a tendência foi de imprimir uma extrema racionalização que negava o uso de EPI para profissionais que não estivessem em contato direto com pacientes com covid-19. Contudo, assistentes sociais, mesmo que não estivessem atendendo diretamente usuários(as) com covid-19, estavam, muitas vezes, atendendo seus familiares. Ademais, no contexto pandêmico, particularmente em se tratando do Sars-CoV-2, a circulação do vírus se dá em diversos espaços no interior e no entorno das unidades de saúde, como foi identificado em algumas pesquisas. ${ }^{11}$

As articulações profissionais no interior dos serviços e fora deles, particularmente com o conjunto CFESS/Cress, com a criação de canais de comunicação remotos pelos Cress para denúncias de violações de direitos, foram fundamentais para a mobilização das equipes de assistentes sociais sobre a garantia do acesso a EPI. O CFESS realizou levantamento junto aos Cress e rapidamente questionou a Agência Nacional de Vigilância Sanitária (Anvisa) que, por sua vez, ratificou a necessidade de uso de EPI pelos assistentes sociais, culminando com o Parecer Jurídico do CFESS no 05/2020-E. ${ }^{12}$

até a data do levantamento, esse total representava apenas $47 \%$ dos hospitais previstos e que não haviam sido entregues (Ribeiro, Pereira e Maurício, 2020).

11 Como o estudo liderado por Lan Ke, diretor do Laboratório Estadual de Virologia da Universidade de Wuhan, publicado na Nature, que indica a presença do vírus em ambientes internos e externos a dois hospitais que atendiam exclusivamente à covid-19 na cidade de Wuhan, China (Veja, 2020).

12 O referido parecer jurídico do CFESS apresenta as demandas e denúncias de violação do direito relacionada ao não acesso adequado a EPI e resgata os fundamentos jurídicos e sanitários 
No que concerne às competências e atribuições profissionais, o documento "Manejo de corpos no contexto do novo coronavírus covid-19", elaborado pelo Ministério da Saúde, recomendou que o Serviço Social realizasse a comunicação de óbito a familiares, amigos e responsáveis durante a pandemia (Brasil, 2020c). Tal demanda, expressa explicitamente pelo Ministério da Saúde, possibilitou que todas as atividades relacionadas à informação e/ou comunicação com as famílias de usuários(as) em tratamento da covid-19, inclusive as de âmbito médico, como os boletins clínicos, fossem requisitadas a assistentes sociais no contexto da pandemia (Matos, 2020b).

Essas requisições não são novas. Reiteram velhas práticas em saúde que concebem as ações da equipe multiprofissional de saúde não médica como mero subsídio ao "ato médico" ou por ele instrumentalizadas. Além disso, também se vinculam às práticas do Serviço Social tradicional ou conservador. Assim, em meio às contradições da política de saúde, com intensa precarização, desfinanciamento, privatização e fragmentação, sem articulação e coordenação de enfrentamento em nível federal, com expressões de uma política genocida ao mesmo tempo que extremamente privatista e ultraliberal, o Serviço Social é requisitado a reproduzir o perfil profissional tecnicista, voluntarista e conservador.

O conjunto CFESS/Cress agiu com rapidez e pertinência, emitindo a Orientação Normativa no 03/2020, que enfatiza que tanto a comunicação de óbito quanto o repasse de informações de âmbito clínico não são atribuições de assistentes sociais. Ratifica, dessa forma, que:

O/A assistente social deve se ater às suas atribuições e competências profissionais, visando o melhor atendimento ao/a usuário/a dos serviços de saúde, preservando a qualidade dos atendimentos prestados, não estando

\footnotetext{
da necessidade do seu uso, bem como da obrigatoriedade de seu fornecimento por parte das instituições empregadoras. Instada pelo CFESS, a Anvisa se pronunciou informando a necessidade de uso de EPI pelos assistentes sociais em todos os serviços de saúde. O CFESS, diante do exposto, recomendou que as situações de violação do direito a acesso a EPI adequado fossem denunciadas aos órgãos competentes (CFESS, 2020a).
} 
obrigado/a a realizar atividade incompatível com a legislação profissional vigente (CFESS, 2020b, p. 2).

Na mesma direção, o artigo produzido por Maurílio Matos (2020a) cumpriu um papel fundamental, não só reafirmando as orientações do CFESS, mas ampliando-as no sentido de caracterizar as mudanças necessárias na organização do trabalho profissional no âmbito dos serviços de saúde e estratégias de distanciamento social e uso de alguns instrumentos remotos, ${ }^{13}$ como o telefone e redes, pertinentes ao contexto da pandemia. Além disso, discute o principal objetivo da atuação profissional na política de saúde e a necessidade de as equipes refletirem coletivamente sobre as prioridades e estratégias de ação.

O objetivo do Serviço Social é a identificação dos aspectos econômicos, políticos, culturais, sociais que atravessam o processo saúde-doença para assim mobilizar recursos para o seu enfrentamento, articulado a uma prática educativa (Matos, 2020a, p. 3).

A despeito da complexidade e das profundas contradições expressas no tempo presente, o Serviço Social brasileiro não fugiu à luta. Diversos(as) assistentes sociais enfrentaram os desafios da agudização das expressões da questão social em tempos de políticas sociais ultraliberais, muitas vezes em equipes temporárias e em situação de contratos temporários.

De fato, assistentes sociais avançaram, desvelando e revelando as expressões da questão social que interferem no processo saúde-doença e

13 Posteriormente, o CFESS lançou Teletrabalho e teleperícia: orientações para assistentes sociais no contexto da pandemia, que, entre outros elementos, discute as diferenças entre trabalho remoto e uso de ferramentas remotas, bem como os cuidados, finalidades, limites e condições éticas e técnicas. Na particularidade do trabalho na política de saúde, tem sido mais comum o uso de ferramentas remotas, algumas delas, inclusive, já de uso frequente do Serviço Social, como o telefone. Dessa forma, o trabalho na saúde não foi caracterizado predominantemente pelo trabalho remoto, sendo este destinado, em geral, apenas a trabalhadores(as) com comorbidades para covid-19 (CFESS, 2020c, p. 7). 
suas particularidades relacionadas à covid-19. Entre essas particularidades, a maior letalidade entre pobres e negros. Segundo Gragnani (2020), em estudo realizado na PUC-Rio, constatou-se que "quase 55\% de pretos e pardos morreram, enquanto, entre pessoas brancas, esse valor ficou em 38\%". Os mesmos pretos e pobres que constituem a maioria dos(as) usuários(as) do Serviço Social

Ademais, foi por meio da articulação coletiva no interior das equipes, da articulação com outros profissionais de saúde dentro dos serviços, da articulação externa aos serviços - com outras equipes de assistentes sociais, criação de grupos de whatsapp de assistentes sociais, articulação com o conjunto CFESS/Cress, com o Ministério Público, com movimentos sociais, com as universidades - que se tornou possível ampliar discussões e qualificar a fundamentação dos tensionamentos necessários, reafirmando-se a demarcação do campo de atribuições do Serviço Social e sua contribuição ao enfrentamento da pandemia no âmbito da política de saúde.

A partir dos depoimentos, ${ }^{14}$ falas em diversas lives realizadas em todo o país com a temática do trabalho profissional de assistentes sociais na saúde no contexto do enfrentamento da covid-19, testemunhamos a coragem e o compromisso ético-político-profissional, muitas vezes sob o risco de adoecimento e perda da própria vida. ${ }^{15}$

Mesmo no bojo de tantas e tão complexas contradições, assistentes sociais exercitaram a relativa autonomia profissional nos termos de Mota e Amaral (2016), incluindo e ultrapassando as relações de trabalho e

14 Realizamos levantamento de informações a partir de depoimentos e falas de assistentes sociais na linha de frente na política de saúde divulgados através de lives dos diversos projetos de extensão realizados pelas universidades em parceria com os Cress em Pernambuco, Rio de Janeiro e Alagoas (que podem ser acessadas nos respectivos canais de YouTube dos referidos Cress), bem como as lives realizadas pela Abepss, entre elas destacamos a do GT de Fundamentos "Precisamos discutir os fundamentos do Serviço Social para responder ao tempo presente!" e o IX Congresso Nacional de Serviço Social em Saúde (Conasss) na modalidade virtual e seus respectivos anais.

15 Em memorial organizado pelo CFESS e pela Abepss - Nosso luto, nossa luta! — constam, até 18/10/2020, 41 assistentes sociais que morreram em decorrência da covid-19 no Brasil. Entre elas, pelo menos treze atuavam na política de saúde (CFESS, 2020d). 
subordinação, avançando em direção à consciência individual e à coletiva, apropriando-se do conhecimento aprofundado sobre a realidade - a partir dos fundamentos da razão dialética -, do conhecimento sobre os projetos em disputa, o arcabouço político-legislativo-institucional e os processos a eles relacionados.

Assim, ao negar a demanda de mero(a) repassador(a) de informação clínica e de comunicação de óbito, de perfil tecnicista, voluntarista e conservador, assistentes sociais contribuíram com capacidade propositiva e estratégias coerentes com suas atribuições e competências profissionais de forma a: participar do planejamento de fluxos de informação nos serviços de saúde; com a defesa de direitos, inclusive o direito à informação e sua democratização; propor protocolos de atendimento qualificados no interior dos serviços, inclusive com minuciosos processos de identificação dos(as) usuários(as) e sua realidade social, dando visibilidade às expressões da questão social na saúde; criar fluxos de articulação com a rede de saúde nos diversos territórios, particularmente entre os diversos níveis de atenção (primária, secundária e terciária); realizar articulação com os diversos serviços socioassistenciais a fim de defender a garantia de direitos dos(as) usuários(as) e a intersetorialidade das políticas no contexto da pandemia; elaborar materiais educativos e de informação em saúde e sobre direitos; realizar ações socioeducativas e de orientação sobre direitos e benefícios, entre eles o auxílio emergencial; ${ }^{16}$ realizar ações socioeducativas que desvelam o discurso negacionista sobre a pandemia junto aos(às) usuários(as) e familiares; articular observatórios de defesa de direitos, junto com o Ministério Público e movimentos sociais; participar ativamente do movimento sanitário ou vincular-se a ele, acompanhando as pautas do movimento na defesa da garantia da vida de todos(as) — pessoa idosa, crianças/adolescentes, pessoas com deficiência, população em situação de rua, população negra, mulheres,

16 Em alguns municípios do país houve sobrecarga de demandas relativas à orientação sobre o auxílio emergencial devido ao fechamento, no início da pandemia, de alguns Centros de Referência de Assistência Social (Cras) e Centros de Referência Especializados de Assistência Social (Creas). 
homens, LGBTQIA+ etc.; elaborar documentos norteadores da defesa de direitos. Enfim, dando uma grande contribuição na defesa da vida, na perspectiva de uma concepção ampliada de saúde vinculada à determinação social, ao projeto de reforma sanitária e a uma sociabilidade emancipada (Soares et al., 2020; Bandeira et al., 2020; Melo et al., 2020).

\section{Considerações finais}

No Brasil, além da crise sanitária de extrema complexidade e gravidade, associada à crise capitalista, temos que enfrentar uma política de saúde sob a gestão de um governo negacionista, protofascista, conservador e ultraliberal. De modo que foi engendrado um verdadeiro processo de desarticulação e de desestruturação técnica do enfrentamento da pandemia da covid-19 em nível federal, contribuindo de forma decisiva para a morte de mais de 150 mil brasileiros. Ao tempo, e dialeticamente, é neste presente que fica evidente a racionalidade destrutiva da sociabilidade contemporânea, que também torna expressiva a necessidade do SUS e a relevância do projeto de reforma sanitária.

Assistentes sociais de todo o país integraram a força-tarefa de trabalhadores(as) da saúde que lutam bravamente na assistência à saúde da população em meio às contradições de uma política extremamente precarizada, desfinanciada e privatizada, instrumentalizada a serviço dos interesses do mercado privado da saúde.

Em meio ao flanco de contradições da pandemia, o Serviço Social, com seu projeto ético-político-profissional, foi capaz de propor as respostas mais qualificadas às demandas complexas da crise sanitária e das expressões da questão social, a partir de estratégias coletivas de reflexão sobre a realidade e o planejamento, articulações interna e externa aos serviços, inclusive junto aos movimentos sociais, potencializando o tensionamento dos limites da relativa autonomia profissional, na defesa do SUS, da reforma sanitária e de uma sociabilidade emancipada. Enfim, na resistência pela vida de todos(as) e contra a barbárie. 


\section{Referências}

AGÊNCIA ESTADO. Com crise, Banco Central já anunciou R\$ 1,2 trilhão em recursos para bancos. Infomoney, São Paulo, 23 mar. 2020. Disponível em: https://www.infomoney. com.br/economia/com-crise-banco-central-ja-anunciou-r-12-trilhao-em-recursos-parabancos. Acesso em: 8 out. 2020.

BANDEIRA, Karla et al. A atuação do assistente social em linhas de frente de Covid-19: reflexões sobre as experiências desenvolvidas em três hospitais de grande porte. IX Conasss, 2020, Ribeirão Preto. Anais. Disponível em: www.conasss.com.br. Acesso em: 6 out. 2020.

BRASIL. Ministério da Saúde. Painel Coronavírus. Portal do Covid-19, 2020a. Disponível em: https://covid.saude.gov.br. Acesso em: 11 out. 2020a.

BRASIL. Ocupação de nível superior total por natureza jurídica. Cadastro de Estabelecimentos de Saúde (CNES), 2020b. Disponível em: http://tabnet.datasus.gov.br/ cgi/tabcgi.exe?cnes/cnv/prid02br. def. Acesso em: 17: set. $2020 \mathrm{~b}$.

BRASIL. Manejo de corpos no contexto do novo coronavírus Covid-19. 1. ed. Brasília: Secretaria de Vigilância em Saúde, 2020c.

BRASIL. Portaria n 639, de 31 de março de 2020. Dispõe sobre a ação estratégica "O Brasil Conta Comigo - Profissionais da Saúde”. Diário Oficial da União, Brasília, 2 abr. 2020d. Seção 1, p. 76.

BRAVO, M. I. S; PELAEZ, E. J.; MENEZES, J. S. B. A saúde nos governos Temer e Bolsonaro: lutas e resistências. SER Social, Brasília, v. 22, n. 46, p. 191-209, 6 jan. 2020.

CFESS. Parecer Jurídico no 05/2020-E, de 24 de abril de 2020. Dispõe sobre a ausência de equipamentos de proteção individual - EPI para assistentes sociais. Brasília: Conselho Federal de Serviço Social, 2020a.

CFESS. Orientação normativa no 3/2020, de 31 de março de 2020. Dispõe sobre ações de comunicação de boletins de saúde e óbitos por assistentes sociais. Brasília: Conselho Federal de Serviço Social, 2020b.

CFESS. Teletrabalho e teleperícia: orientações para assistentes sociais no contexto da pandemia. Brasília: Conselho Federal de Serviço Social, 2020c. Disponível em: http://www. cfess.org.br/arquivos/Nota-teletrabalho-telepericiacfess.pdf. Acesso em: 17 out. 2020.

CFESS. Memorial nosso luto, nossa luta! Brasília: Conselho Federal de Serviço Social, 2020d. Disponível em: http://www.cfess.org.br. Acesso em: 17 out. 2020.

CNS. Recomendação no 22, de 9 de abril de 2020. Recomenda medidas com vistas a garantir as condições sanitárias e de proteção social para fazer frente às necessidades emergenciais da população diante da pandemia da Covid-19. Brasília: Conselho Nacional de Saúde, 2020a. 
CNS. Petição pública: O SUS merece mais em 2021. Conselho Nacional de Saúde, Brasília, 2020b. Disponível em: http://www.conselho.saude.gov.br/ultimas-noticias-cns/1297peticao-publica-voce-vai-deixar-o-sus-perder-mais-r-35-bilhoes-em-2021. Acesso em: 18 out. 2020.

COELHO, H.; BRITO, C. Esquemas de corrupção desviaram quase R $\$ 1,8$ bilhão da Saúde do RJ desde 2007. G1, Rio de Janeiro, 29 set. 2020. Disponível em: https://g1.globo.com/ rj/rio-de-janeiro/noticia/2020/09/29/esquemas-de-corrupcao-desviaram-quase-r-18bilhao-da-saude-do-rj-desde-2007-valor-supera-gastos-com-a-pandemia.html. Acesso em: 19 out. 2020.

CORONAVÍRUS PODE PERMANECER no ar de lugares sem ventilação, aponta estudo. Veja, São Paulo, 20 abr. 2020. Disponível em: https:/veja.abril.com.br/saude/coronavirus-podepermanecer-no-ar-de-lugares-sem-ventilacao-aponta-estudo. Acesso em: 15 out. 2020.

CORREIA, M. V. C.; ALVES, P. K. L. Pandemia, desigualdade social, determinação social do processo saúde e doença: quem são os mais atingidos? In: CORREIA M. V. C; LIMA, A. S. (orgs.). Pandemia, determinações da Saúde e enfrentamento da Covid-19: o lucro acima da vida. Maceió: Edufal, 2020a.

CORREIA, M. V. C.; ALVES, P. K. L.. O apoio do Estado à saúde suplementar no enfrentamento da Covid-19 no Brasil. In: CORREIA, M. V. C.; LIMA, A. S. (orgs.). Pandemia, determinações da saúde e enfrentamento da Covid-19: o lucro acima da vida. Maceió: Edufal, 2020b.

FONTES, Virgínia. O núcleo central do governo Bolsonaro: o protofascismo. Racismo Ambiental, Rio de Janeiro, 11 jan. 2019. Disponível em: https://racismoambiental.net. br/2019/01/11/o-nucleo-central-do-governo-bolsonaro-o-proto-fascismo-por-virginiafontes. Acesso em: 18 out. 2020.

GRAGNANI, Juliana. Por que o coronavírus mata mais as pessoas negras e pobres no Brasil e no mundo? BBC Brasil, 12 jul. 2020. Disponível em: http://www.bbc.com/portuguese/ brasil-53338421. Acesso em: 10 out. 2020.

MATOS, Maurílio. A pandemia do coronavírus (Covid-19) e o trabalho de assistentes sociais na saúde. Rio de Janeiro: Cress, 6 abr. 2020a. Disponível em: http://www.cress-es.org.br/ wp-content/uploads/2020/04/Artigo-A-pandemia-do-coronav\%C3\%ADrus-COVID-19e-o-trabalho-de-assistentes-sociais-na-sa\%C3\%BAde-2.pdf. Acesso em: 17 set. 2020.

MATOS, Maurílio. (Des) informação nos serviços de saúde em tempos da pandemia da Covid-19: uma questão ética e uma requisição enviesada ao trabalho de assistentes sociais. Rio de Janeiro, 11 ago. 2020b. Disponível em: https://drive.google.com/file/d/1TJ Pr4svDJJamlocu1SOSvwF1jv5u7eYo/view. Acesso em: 17 out. 2020.

MELO, Delaine et al. Atenção primária à saúde, pandemia da Covid-19 e atuação profissional do/a assistente social. IX Conasss, 2020, Ribeirão Preto. Anais. Disponível em: www.conasss.com.br. Acesso em: 6 nov. 2020. 
MOTA, A. E.; AMARAL, Â. Serviço Social brasileiro: cenários e perspectivas nos anos 2000. In: MOTA, A. E.; AMARAL, Â. Cenários, contradições e pelejas do Serviço Social brasileiro. São Paulo: Cortez, 2016.

OPAS BRASIL. Folha Informativa Covid-19. Disponível em: https://www.paho. org/bra/ index.php?option=com_content\&view $=$ article\&id=6101:covid19\&Itemid=875. Acesso em: 14 jun. 2020.

POLÍCIA FEDERAL. Polícia Federal deflagra operação SOS para combater desvios de recursos públicos na saúde. Brasília: Polícia Federal, 29 set. 2020. Disponível em: https:// www.gov.br/pf/pt-br/assuntos/noticias/2020/09-Noticias-de-setembro-de-2020/pfdeflagra-operacao-s-o-s-para-combater-desvios-de-recursos-publicos-da-saude. Acesso em: 18 out. 2020 .

RIBEIRO, D.; PEREIRA, G.; MAURÍCIO, T. Só 47\% dos hospitais de campanha previstos no Brasil já foram entregues. CNN Brasil, 28 maio 2020. Disponível em: https://www. cnnbrasil.com.br/saude/2020/05/28/so-47-dos-hospitais-de-campanha-previstos-nobrasil-ja-foram-entregues. Acesso em: 16 out. 2020.

SOARES, Raquel C. Contrarreforma no SUS e o Serviço Social. Recife: Ed. UFPE, 2020.

SOARES, Raquel et al. A pandemia da Covid-19 e a atuação do Serviço Social na linha de frente: tendências, desafios e estratégias. IX Conasss, 2020, Ribeirão Preto. Anais. Disponível em: www.conasss.com.br. Acesso em: 6 nov. 2020.

TAJRA, Alex. Todos nós vamos morrer um dia: veja falas de Bolsonaro sobre o coronavírus. UOL, São Paulo, 1 maio 2020. Disponível em: https://noticias. uol.com.br/saude/ultimasnoticias/redacao/2020/05/01/todos-nos-vam os-morrer-um-dia-as-frases-de-bolsonarodurante-a-pandemia.htm. Acesso em: 8 out. 2020.

\section{Sobre as autoras}

Maria Valéria CoRreia - Pós-doutora em Serviço Social e professora do Programa de Pós-Graduação em Serviço Social.

E-mail: correia.mariavaleria@gmail.com

Raquel Cavalcante Soares - Doutora em Serviço Social e professora do Departamento de Serviço Social.

E-mail: quelcsoares@gmail.com

Viviane Medeiros - Doutoranda em Serviço Social.

E-mail: vivianemedeiros.al@gmail.com 